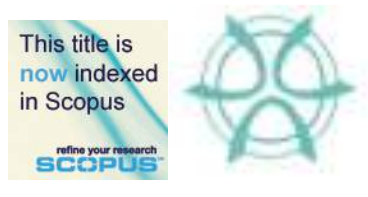

PLANNING MALAYSIA:

Journal of the Malaysian Institute of Planners

SPECIAL ISSUE IV (2016), Page 369 - 382

\title{
RESEARCH FOR A COMPREHENSIVE AND ACTIVE PLANNING METHOD IN AN INDUSTRIAL-RESIDENTIAL MIXED AREA- FOCUSED ON OTA CREATIVE TOWN VISION IN OTA WARD, TOKYO
}

\author{
Taku Nohara ${ }^{1}$, Yu Okamura ${ }^{2} \&$ Susumu Kawahara ${ }^{3}$ \\ ${ }^{l}$ YOKOHAMA NATIONAL UNIVERSITY, JAPAN \\ ${ }^{2,3}$ TOKYO METROPOLITAN UNIVERSITY, JAPAN
}

\begin{abstract}
Recently in Japan, the urban environment in industrial cities has been changing due to changes in the industrial, economical, and social structure. Ota Ward in Tokyo has small industrial districts, some of which are mixed-use areas. In the 1980's there were 9,000 factories, but currently that number has been decreasing and although the factories still possess sophisticated skill-sets, their working environment is inadequate as it is surrounded by too many residential dwellings. In addition, it is too difficult to pass technical knowledge onto succeeding generations. In this research, we focus on a comprehensive and active planning method, specifically, on how to integrate manufacturing, community development, and city promotion so as to solve this kind of problem in mixed residential-industrial cities. Firstly, we investigated the local resources, which consisted of a small industrial network of a "mixed-used" status in Ota Ward that had access to an international airport. Secondly, we created a vision encompassing these three points: (1) Stock (property) management, (2) Supporting Creative Industry, and (3) City Promotion via Industrial Tourism.Currently two projects are in progress: One is the industrial tourism event, "Ota Open Factory", which is a one day program where many restricted access small factories are opened to the public in the mixed-used industrial area; and the other is "Creative Town Lab. Tamagawa", which is an active community space (usable for education, workshops, meetings, exhibitions, events) that has been converted from a vacant factory.With these projects, we are trying to realize the area's potential through activities, recreating a more creative and active city culture and identity.
\end{abstract}

Keyword: Industrial area; Stock Management; Creative Industry; City Promotion; Comprehensive Planning

\section{INTRODUCTION}

Recently in Japan, the urban environment of its industrial cities has been changing due to corresponding dynamic changes in the industrial, economical, and social structure of the country. The "old" type of industrial city is experiencing a gradual decline with the number of their factories and populations decreasing; and this is especially so in industrial-residential mixed-use areas, where factories are disappearing at an incredible 
Taku Nohara, Yu Okamura \& Susumu Kawahara

Research for a Comprehensive and Active Planning Method in an Industrial-Residential Mixed Area-Focused on Ota

Creative Town Vision in Ota Ward, Tokyo

rate and the cities' themselves are becoming increasingly chaotic. Therefore, a strategy to regenerate these industrial cities is very important.

In general, the objective of modern urban planning theory is to create a comfortable urban environment by ejecting from it the worst aspects of the industrial area, such as pollution. One problem, however, is that industrial technology and the environment are changing, and changing rapidly. Industrial areas now additionally function as a source of economic value, and it is important to integrate this production function into urban spaces from the point of view of job creation.

Before the modern era, the productive function coexisted with the living function in many cities, and recently, a job glut has caused an outflow of population from the local cities in Japan, and it is no longer possible to both work and live in the city. Therefore, we have to "re-claim" industry as local value, and to do this it is necessary to rebrand a city's image evoking a fusion of the industrial and urban.

In this research, we focus on a comprehensive and active planning method, specifically, on how to integrate manufacturing, community development, and city promotion so as to solve this kind of problem in mixed residential-industrial cities, and in particular in Ota Ward, Tokyo, Japan. Ota Ward in Tokyo has small industrial districts, some of which are mixed-use areas.

\section{FRAMEWORK}

This research outlines our attempt to establish a framework for a comprehensive planning method, which we have named "creative town making with community development and fabrication" (CTMCDF), by approaching the task from a variety of viewpoints.

First, we attempted to achieve urban regeneration of the industrial city through an integrated planning methodology. Specifically, we took three core approaches, "industrial development", "community development", and "city promotion", and we deliberated on how to link these together.

One of the drawbacks of "sectionalism in Japan, i.e., when one or more urban policies are introduced by the local government, has been pointed out. In Ota Ward, the role of the department in the local government office in relation to CTMCDF is ambiguous, potentially spanning across so many fields (industrial development department, community development department, tourism department etc.), and so the cooperation between each department is not necessarily smooth shows in Figure 1.

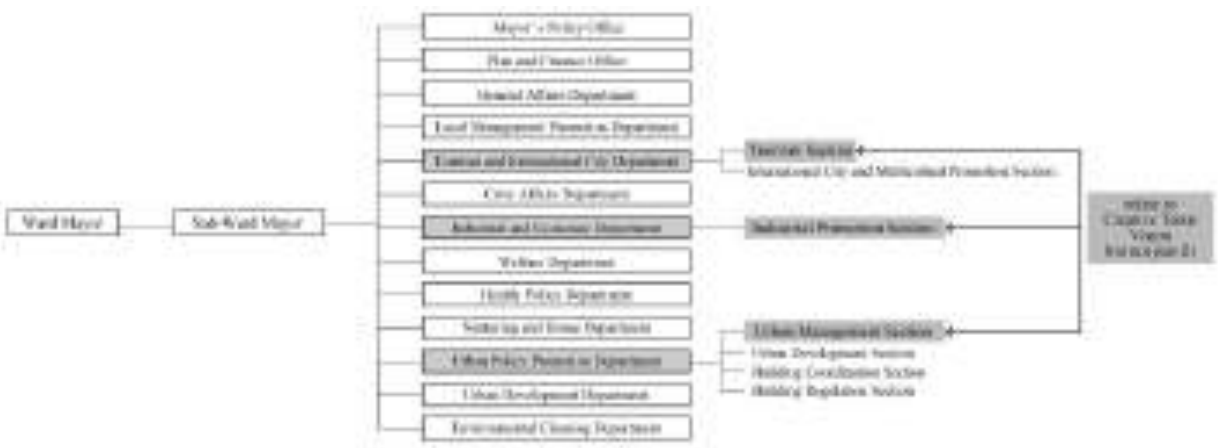

Figure 1: Administration system (department and section chart) in Ota ward, 2015 
To overcome these obstacles, we have tried to consolidate and enhance the borderdomain programs through public-private-academic partnerships. In detail as illustrate in Figure 2, we have attempted to link each department explicitly to the three programs: (1) Supporting Creative Industry (in industrial development), (2) Stock Management (in community development), and (3) Industrial Tourism (in city promotion). This point is explained further below.

The second viewpoint looks at how the following phase-in frames practically achieve urban regeneration. The four phases are: (1) research of local resources and capital, (2) comprehensive planning, (3) social experiments, and (4) review and examination of the realization of the above-mentioned integration approach.

Recently, a "Creative City Policy" has been introduced in many cities around the world, for example, 69 cities joined the Creative Cities Network organized by UNESCO in 2014. This is a comprehensive approach incorporating culture, art, industry, urban design, etc., but the particular interest expressed by the theme of many cities is centered on art and culture (creative cities are classified by Literature, Film, Music, Crafts and Fork Art, Design, Media Arts, and Gastronomy), and not mechanical fabrication itself. Therefore, what we want to do is put the focus on fabrication and industry.

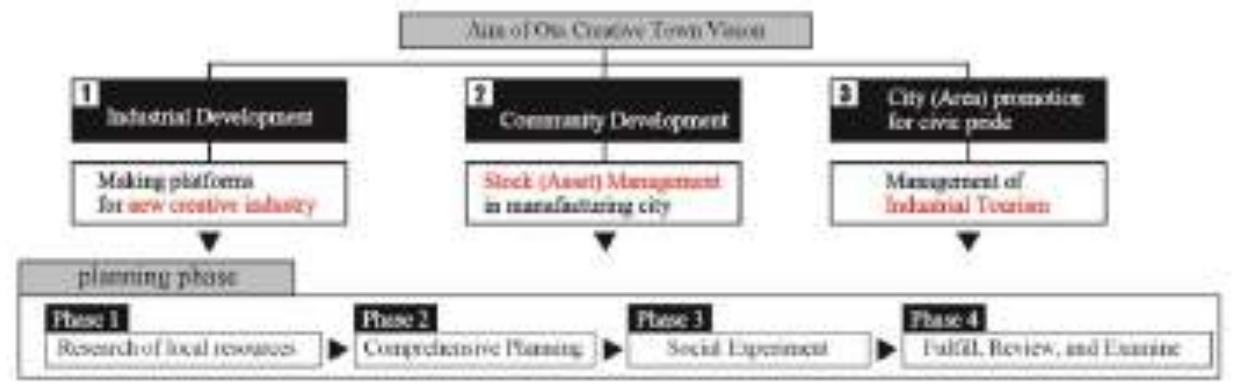

Figure 2: Planning Framework for the Ota Creative Town Vision

\section{HISTORY AND CURRENT SITUATION OF OTA WARD}

\section{Ota Ward in Tokyo: History as an Industrial City}

The history of the Ota Ward industrial city started with the construction of the Tokyo Gas Omori Factory in 1906, with some areas in OTA being assigned to the Industrial Area under the Urban Planning Act of 1919. At that time, however, not only were normal factories engaged in effective production, but they were at the forefront, with several creative factories beginning to accumulate in the area (e.g. a typewriter factory established together with the residential village, an elevator factory, a glass factory etc.). Further developments of 44 residential areas in OTA ward using the Land Consolidation Method (3,003ha in total), and in particular in the Shimo-maruko Area, established a new industrial city composed of factory blocks and residential blocks. This was followed by the cutting-edge companies that began to arrive around that time.

After the Second World War when large factories began to accumulate in the 1950s, the small and medium size factories also began to accumulate around the former fields or workplaces surrounding the fishing village. At the same time, the pollution 
Taku Nohara, Yu Okamura \& Susumu Kawahara

Research for a Comprehensive and Active Planning Method in an Industrial-Residential Mixed Area-Focused on Ota

Creative Town Vision in Ota Ward, Tokyo

problems associated with factories began to appear near and inside the residential areas. This marked the birth of the so-called "problem of industrial-residential mixture".

As a counter-measure, the policy of "industrial-residential separation" was devised and attempted. Ota Ward tried to move the small factories into the new industrial area on the reclaimed land (Heiwa-jima land [1967], Showa-jima land [1967], Keihin-jima land [1974], and Jonan-jima land [1979]) and in the seaside area. Additionally an area was assigned exclusively for industrial use (in Omori-minami, Higashi-kojiya, Hanedaasahicho, and that reclaimed land in 1973), under the Town Planning and Zoning Act of 1968. Unfortunately, in spite of much effort, the situation did not improve. After the 1980s, the strategic focus shifted towards "industrial-residential harmonization" and factories were built in the so-called "factory apartment" style. Several "factory apartments" were established in the area, but they could never seem to obtain a satisfactory arrangement of the land use structure.

\section{Current Situation in Ota Ward}

Nowadays, Ota Ward continues to possess several mixed-use areas (very small factories mixed together with housing areas), but the total number of factories has been decreasing (from 9,177 factories in 1983 to 3,788 factories in 2011, Figure 3), and consequently economic power has been declining as well. After the factory-work came to a halt, new small apartment houses or residences were haphazardly built over that space and the situation only continued to deteriorate. Some factories are still active and can boast of sophisticated capabilities and skill-sets but their working environment is inadequate, being surrounded by too many dwellings, and there are great obstacles to passing the baton that is their technical knowledge onto the next generation, increasingly necessary because of the ageing workforce. Thus, there are at hand several difficult problems that need to be solved.

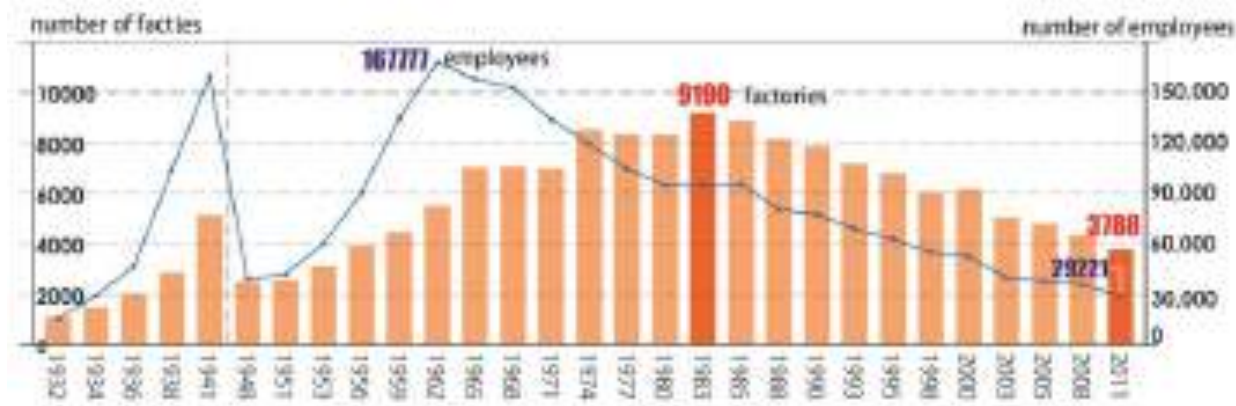

Figure3: Number of factories and workers (Industrial statistics for 2011)

\section{RESEARCH OF LOCAL RESOURCES}

\section{Local resource in fabrication: industrial networks}

Although the number of factories is decreasing, the remaining small factories do in fact have high technological performance and an industrial culture that accepts orders from the major companies in global business. Even if each is factory itself is quite small and 
possesses primarily only specialized techniques (for example, cutting, plating, or polishing), they also participate in a deep cooperative network that exists between the managers of the small and medium size factories, called the "flat contact network" or "bicycle network" (signifying that the diverse factories of the network are at a very short distance from one another), and this network has developed through both formal and informal local interaction.

For example, the existing literature about the Omori-Minami area in Ota ward (Okuma and Nohara, 2010) shows that they have autonomous industrial and social networks in this local area (Figure 4). In Shimo-maruko Area in particular, "Kowa-kai", which is a local industrial guild organization, operates with approximately 150 small manufacturing companies in Ota Ward having joined. This organization is a real genuine local resource tying together the area and the industries.

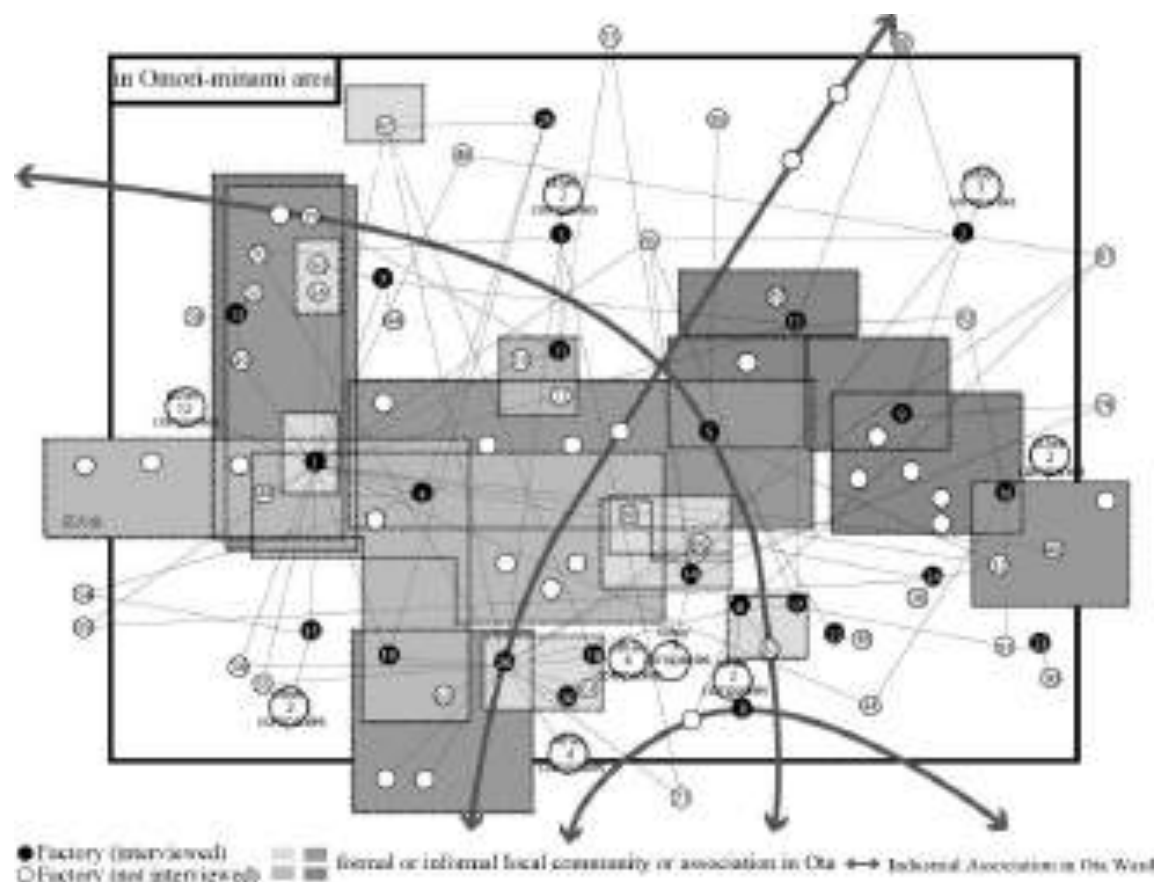

Figure 4: Industrial (small factories) and social network in the local area Source: Okuma and Nohara, 2011

\section{Stock resource in industrial area}

\section{Stock resource: factory as an architectural type}

If we re-conceptualize the factories as spatial stocks and asset stocks, we can find the architectural characteristics of a factory: they have the atmosphere of a workspace, have large opening doors, crane facilities for machine import, large-capacity power supply facilities, and so on. 
Taku Nohara, Yu Okamura \& Susumu Kawahara

Research for a Comprehensive and Active Planning Method in an Industrial-Residential Mixed Area-Focused on Ota

Creative Town Vision in Ota Ward, Tokyo

Although there were over 1,100 factories in 1973 in the Shimo-Maruko area, a mixed industrial-residential area in OTA, presently there are under 400 (having been converted mainly into residences or parking); however, there are still quite a few "charming" buildings, which we call"Live-Fab. Buildings", referring to a certain architectural typology in which the ground floor is for factory use and the higher floors are residential. There are over 200 such buildings in the area.

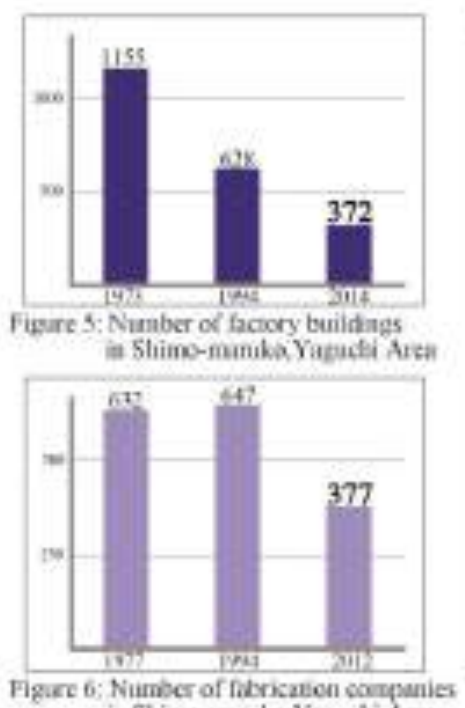

in Shimb-maruka, Yampiti Arsa

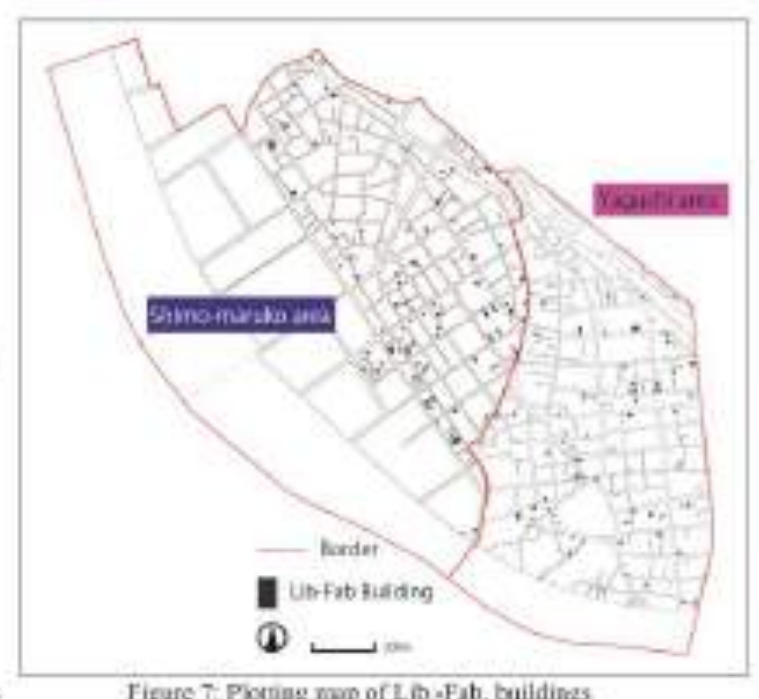

in Shimo-namion, Yavedii Arva

Source: Ota Creative Town Study Group, 2015

\section{Stock network in industrial area}

This area is home to several complicated networks interweaving between fabrication and local life. For example, 35\% of land in this area illustrate in Figure 9 belongs to owners who are concerned with factories and manufacturing. Many factory owners are very important players because they have multiple roles, for example, not only acting as the president of a fabrication company, but also as a building and land owner, and even as a resident of the area. Research of the Kowa-kai association has revealed that $82 \%$ of factory managers live in Ota Ward, and so they are closely connected to the area display in Figure 8. 


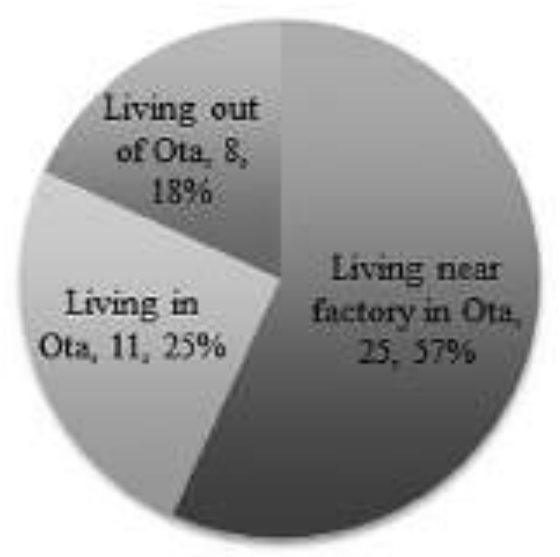

Figure 8: Living situation for factory managers in OTA $(n=44)$
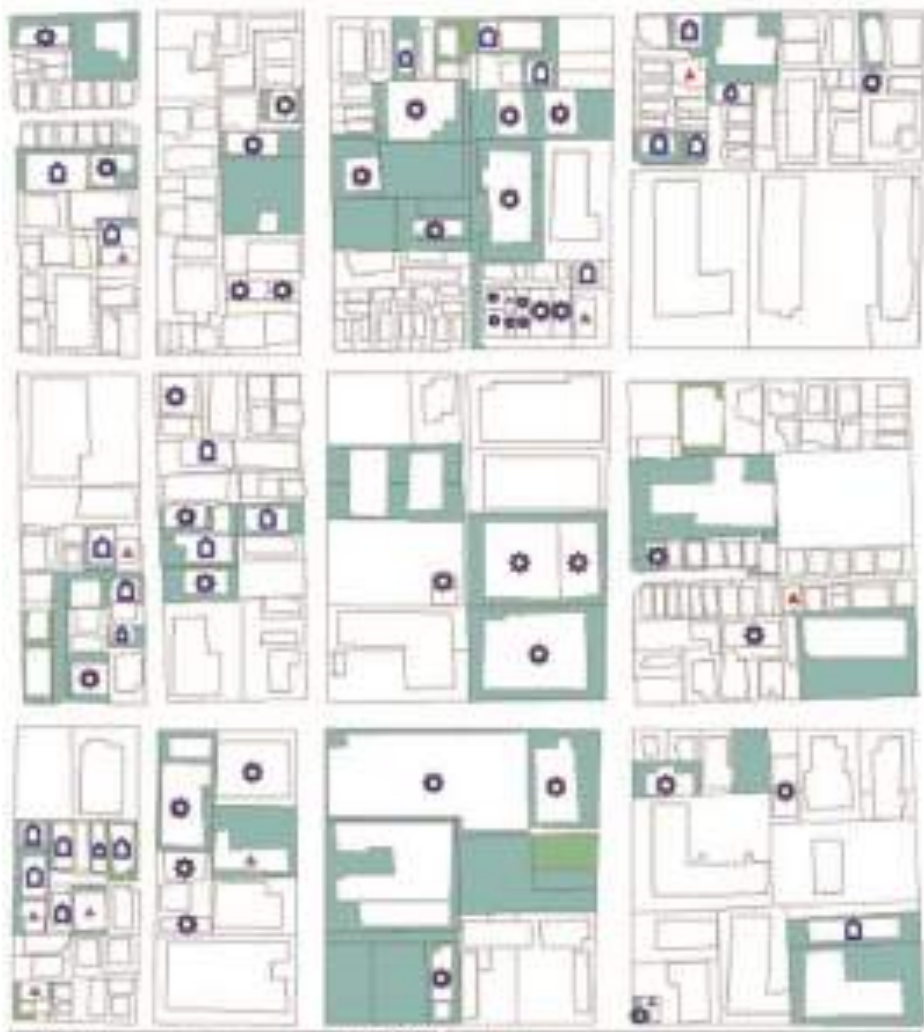

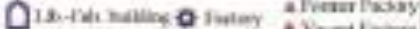

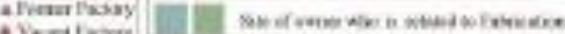

Figure9: Structure of land-building owning and using in Lib-Fab area in Ota Source: Ota Creative Town Study Group, 2015 
Taku Nohara, Yu Okamura \& Susumu Kawahara

Research for a Comprehensive and Active Planning Method in an Industrial-Residential Mixed Area-Focused on Ota

Creative Town Vision in Ota Ward, Tokyo

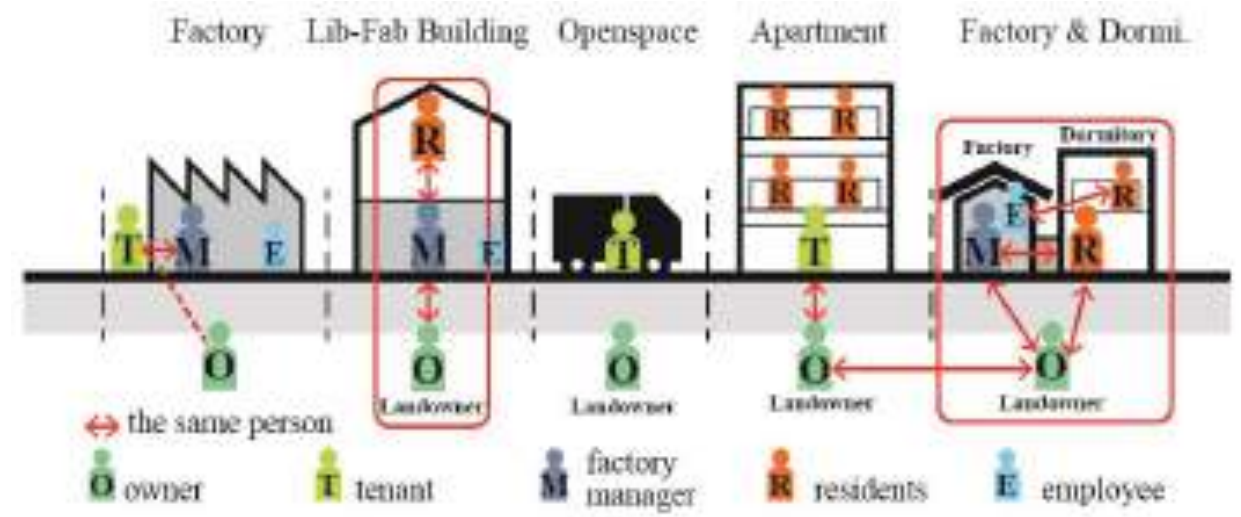

Figure10: Structure of land-building ownership and use in Lib-Fab area in Ota

\section{Resource for industrial tourism}

Recently, the demand for industrial plant tours for ordinary citizen has been increasing because it is nowadays impossible to fully understand or grasp the behind the scenes processing of one's desired finished product at the time of purchase. As a result, a new kind of tourism, "industrial tourism" has been experiencing rapid growth.

Furthermore, by considering the whole Ota Ward rather as an undeveloped section of the industrial area, the possibilities for industrial tourism become evident. Ota Ward is a big city with a population of approximately 700,000 . It is richly diverse, featuring an upper-class residential area on plateaus, many attractive shopping streets, and the Haneda International Airport, the base of globalization. Seen in terms of industrial tourism, such local variety has definite possibilities for the future.

\section{COMPREHENSIVE PLANNING: OTA CREATIVE TOWN VISION (2011)}

\section{Ota Creative Town Vision (2011)}

We created the "Ota Creative Town" Vision in collaboration with the Ota Tourist Association and two Universities (Tokyo metropolitan Univ. and Yokohama National Univ.), supported by the local authorities (Ota Ward). Through this Vision, we have aimed at a new solution by creatively reconsidering and investigating the problems and resources of each field ('industrial development', 'community development', and 'city promotion'). To solve these problems we set the following three aims: (1) Create platforms for new creative industries, (2) Expand the base of manufacturing by industrial tourism, and (3) Regenerate attractive urban spaces in the industrial city using Stock (property/real estate) management

(1) Creating platforms for new creative industries : this goal is all about creating new industries by matching fabrication with creative work (for example Art, Design, IT Venture, Medical science). To create products not only for businesses but also for consumers, we want to utilize platforms for idea and information collection and creative networking. More concretely, we have carried out several projects: the "Ota select shop 
project" collected attractive products made in the Ota area, the "ART-FACTORY matching project" matched craftsmen with creators, and the "Manufacturing Egg Project" involved making an original capsule toy to bring consumers closer to the actual fabrication process.

(2) City promotion and Expansion of the footprint of manufacturing through an industrial tourism event: this aim not only relates to the growth of manufacturing itself, but also the to the spread of knowledge about fabrication to consumers and the local people who have not been in close proximity to industry before, helping them understand the manufacturing environment and the importance of culture as a source of the city's burgeoning identity. To realize this, we are trying to organize "Ota open factory", an industrial tourism event in which many small factories will be open to consumers and visitors. We have also suggested designating an area (tentatively called "Mono-machi Cafe") for interaction between craftsmen, factory workers, creators, and consumers and locals.

(3) Regeneration of attractive urban space in industrial cities using stock management: here we aim at the enhancement of amenity and comfort in factory spaces in order to allow for pleasant and effect work to be performed and to put vacant stocks (factories and buildings) to a creative use (craft space, community space, atelier, or other creative spaces). We have proposed several projects as follows. "Live-Fab building" will investigate attractive buildings such as small characteristic factories with overhead living space, "Ota real estate project" will consider potential uses of buildings or spaces, and "Fabrication and community development base" (hereafter called Creative Town Lab.) will propose use of vacant space as the core site of other activities.

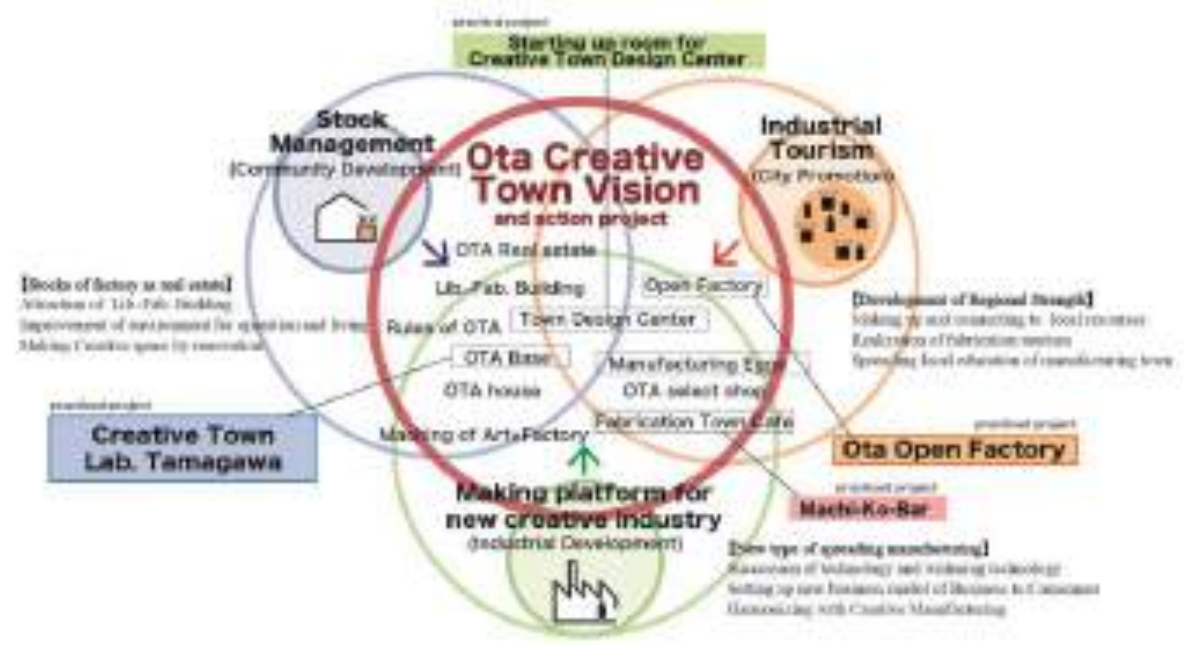

Figure 11: Schematic diagram of Ota Creative Town Vision 
Taku Nohara, Yu Okamura \& Susumu Kawahara

Research for a Comprehensive and Active Planning Method in an Industrial-Residential Mixed Area-Focused on Ota

Creative Town Vision in Ota Ward, Tokyo

\section{Planning Process}

The planning processes outlined below were followed to drive forward and practically implement the Ota creative town vision.

(1) Research of industrial spaces in the Ota area : to clarify the charm (product, technique, craftsman, factory architecture, space) as a variety of resources about manufacturing (about total 70 factories), we studied factory spaces and interviewed craftsmen and factory managers. Then, we studied the historic changes of the area and the land use and building stocks of the manufacturing area to understand how to approach the regeneration of the city.

(2) Small social experiments: next, we carried out small-scale experiments (as outlined above) to clarify which were the attractive and important aspects of the area. We planned and carried out the "Ota city walk of the manufacturing area" around factories and surrounding areas in 2009 and 2010, and also developed "Monodukuri Tamago (Manufacturing Egg)" in 2010, a capsule toy product made in Ota with the cooperation of a factory and based on a student's idea. In addition, we announced and displayed these results at an industrial event (OTA INDUSTRIAL FAIR) in Ota in order to solicit further advice and suggestions.

(3) Comprehensive planning ("Ota Creative Town Vision"): for the actions mentioned above we have proposed a vision and plan (Ota creative town vision, 2011) drawn up in "Ota Mono-machi BOOK 2011" (2011). In the plan, the three aims and directions (new industries, industrial tourism, and stock management) and an action plan (the drafting of the project and the practice process) are detailed.

(4) Social experiment and adjustment: Since it has been difficult to immediately carry out and make our vision a reality, we began with several easily executed social experiments: "Manufacturing Egg" (development of new creative products), "Ota Open Factory" (industrial tourism event), and "Creative Town Lab. Tamagawa" (stock management).

Initially the projects were not met with a resoundingly warm welcome by the factory owners and workers, and the community organization was averse to any changes to the present conditions that would occur as a result of the social experiments based on our vision. Nevertheless, we were gradually able to conduct bigger social experiments by accumulating a record of several small successful attempts which acted as proof of concept allowing us to convince the craftsmen, building and factory owners, and the local people of the value of what we were doing. Moreover, these experiments were carried out flexibly and according to each specific situation. For example, the useful vacant space that was discovered while we ran "Ota Open Factory" led to the next social experiment, "Creative Town Lab. Tamagawa.

\section{SOCIAL EXPERIMENTS}

As of the publication of this study, the following two projects have been fully completed.

\section{"Ota Open Factory"}

One project that embodied our vision was an industrial tourism event, "Ota Open Factory". This is an annual program in which many small factories in the riverside residential-industrial mixed areas, Shimo-maruko, and Yaguchi area, are opened to the 
public. At this time, the public can not only visit working factories, but also talk with active craftsmen, observe the manufacturing workshops, join in factory tours, receive authentic goods, and even simply ramble around the area. This event is carried out by the "Ota Open Factory Committee", which is comprised of the "Ota Creative Town Study Group", consisting of the Ota Tourist Association, two Universities (Tokyo Metropolitan Univ. and Yokohama National Univ.), “Kowa-kai”, and some individual factory managers.

We have held this event four times (Feb 2012, Dec 2012, Feb 2014, Nov 2014), and although occasionally we have experienced bad weather (snow, typhoon, rain) many guests have participated with about 1,200 people attending the first event and up to about 2,000 people attending the fourth. The guests consisted not only craftsmen or workers in the same trade from other cities, but also local people and those concerned with manufacturing and factories. At the first event 31 companies participated or opened and this more than double by the fourth event with 71 companies participating.

\section{"Creative Town Lab. Tamagawa"}

The other project successfully carried was"Creative Town Lab. Tamagawa, which involved the conversion of vacant space (formerly used as factory or office space until several years ago) to active community space for a fabrication town. It was introduced when we were planning the Open Factory Event, and the Ota Tourist Association rented it from the owner and converted it. During planning, we commandeered the area and used it variously as an educational space to learn about manufacturing and absorb information about the city, a workshop space, a meeting or an exhibition space that the size limitations of small factories simply do not allow for, a window of the tour, exhibition space, and a café-bar for social interaction. In particular, we planned this space for events to show the atmosphere of a creative factory town (charming craftsmen, detailed industrial techniques, town history etc.) for local residents. It was used around 30 times per year from December 2013 for events featuring manufacturing craftsmen, workshops for children, and so on. All users were satisfied.

\section{Assessment of this plan and future projects}

We conducted a questionnaire survey to evaluate the "Ota creative town vision" and some future projects to further the enactment of our vision.

First, 140 participants of the Ota Open Factory Event (the fourth, in November 2014) were surveyed. The question we asked was "What kind of interest do you have in the Ota Open Factory Event". We received many different answers, such as "to talk with the craftsmen" (largest number of answers), "to experience the high technology that a factory of Ota has", "to see the cityscape of the factory buildings" and so on; and from this we understood that the participants had a variety of interests in the event.

In addition, for the question "what would you do in an industrial-residential mixed city", the answers were "support small factories in towns", "raise up a new generation of craftsmen", and "develop original products"; and from this it is clear that manufacturing in OTA is highly-rated and the object of great expectations.

For the factories that were members of "Kowa-kai", we also conducted a separate questionnaire survey concerning their image of the architectural future of their factory (56 answers were returned, a recovery rate of $47 \%$ ). Although approximately $40 \%$ were 
Taku Nohara, Yu Okamura \& Susumu Kawahara

Research for a Comprehensive and Active Planning Method in an Industrial-Residential Mixed Area-Focused on Ota

Creative Town Vision in Ota Ward, Tokyo

satisfied with the current conditions, 36 companies intended to update their factory institutions, and 10 companies intended to expand the open space in their factories; for example, the interchange space, the creative space, the exhibition space, and the rest space. This shows that there is in fact the possibility of space re-arrangement that industry space and city space are related to. The potential of industrial tourism was evident in the acceptance of plant tours by 21 companies. We also understood that most factories expected the entry of a new company including a creator or the venture company.

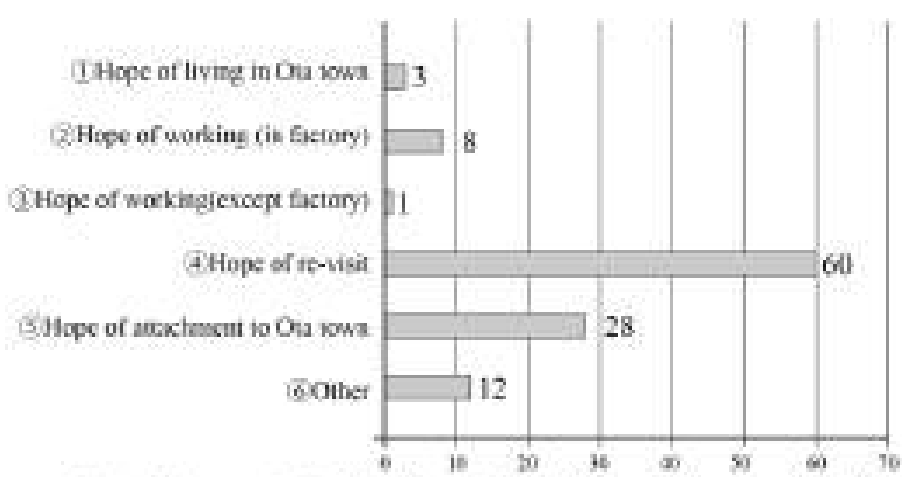

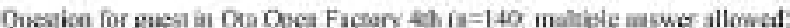

Whe kind of impression of Oia do you hwe afler evere?

Figure 12: Impression after Open Factory

$(\mathrm{n}=140 ;$ multiple answer allowed $)$

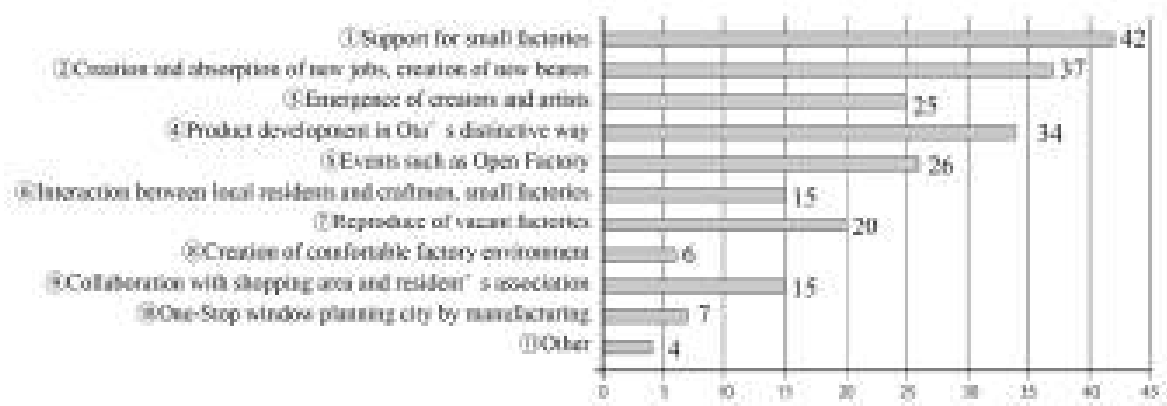

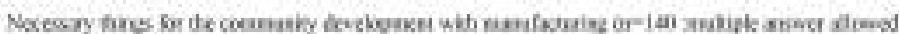

Figure 13: Necessary Things for Community Development

( $\mathrm{n}=140 ;$ multiple answer allowed) 


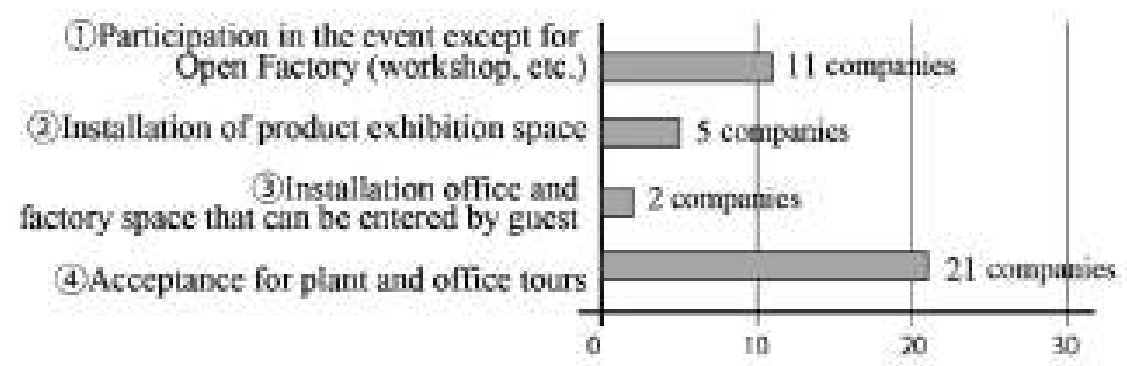

\section{Question: Participation intention for factory open events} ( $\mathrm{n}=56$ :multiple answer allowed)

Figure 14: Intention of Participation in event $(\mathrm{n}=56$; multiple answer allowed $)$

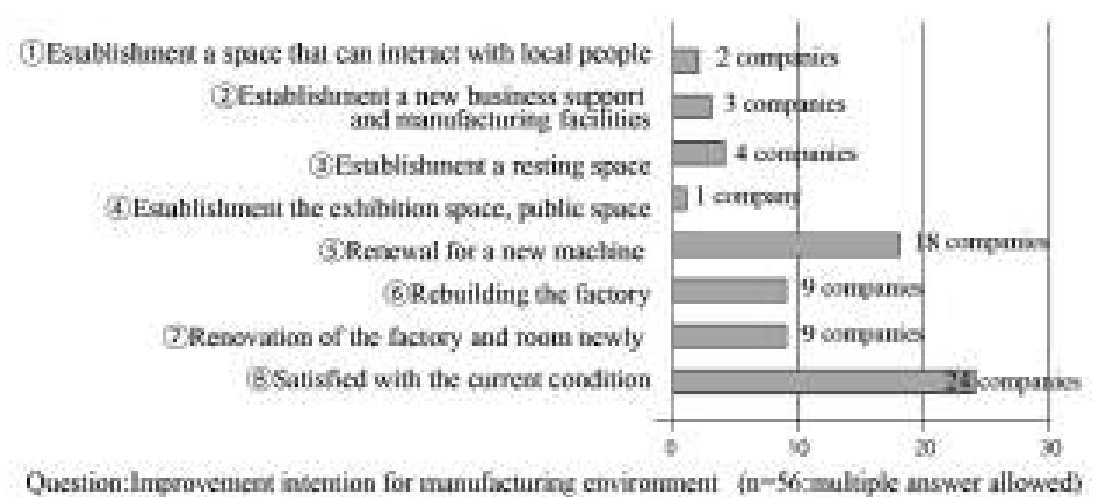

Figure 15: Intention of Improvement of factory $(\mathrm{n}=56$; multiple answer allowed $)$

\section{CONCLUSION}

This study aimed at acquiring a methodology for the regeneration of the living environment and industrial spaces of industrial-residential mixed-use cities through comprehensive planning and the implementation of practical projects. We attempted to match an area's potential to a corresponding activity and to forge a new city identity of creativity and action.

First, we investigated local resources in the residential-industrial mixed area for sustainable urban planning. As a result, we found the existence of a number of attractive buildings, including a mixed living and fabrication type, and also the existence of a social industry network or industrial organization at the local level, despite the fact that the number of factories in itself had decreased.

In addition, we drew up the "Ota Creative Town Vision" as an integrated plan and established several projects to realize three aims: (1) Create platforms for new creative industries, (2) Expand the footprint of manufacturing by industrial tourism, and (3) 
Taku Nohara, Yu Okamura \& Susumu Kawahara

Research for a Comprehensive and Active Planning Method in an Industrial-Residential Mixed Area-Focused on Ota

Creative Town Vision in Ota Ward, Tokyo

Regenerate attractive urban space in industrial cities using Stock (property/real estate) management.

After some adjustment, we ran two social experiment projects, "Ota Open factory Event", conducted from the viewpoint of industrial tourism, and "Creative Town Lab. Tamagawa", conducted from the viewpoint of stock management.

Furthermore, through the answers obtained from questionnaire surveys we came to understand that there were a variety of needs and high expectations for manufacturing. Many factories are willing to update their facilities and intend to put the expansive space in the case of update inside at the same time.

This research is still in progress, and through further investigation and inspection we will try to advance the project to the next stage of developing a creative town strategy and rebuilding the industrial space.

\section{ACKNOWLEDGMENT}

This work was supported by a JSPS KAKENHI Grant in Aid for Scientific Research No.24560740, "Research for the area management method with area-conversion in industrial -residential mixed used area," and No. 15K06350 "Research for possibility of establishment and development of area-conversion method with industrial characteristics in local area." And this was supported by technical staff (Natsumi Abe).

\section{REFERENCES}

Mizuki Okuma, Taku Nohara. (2011). 'A Study on the Network Based on the Industrial Co-operation in the Residential-Industrial Mixed Used Area -Focused on the Residential-Industrial Mixed Use Area in Omori Minami Area in Ota-ku-', Japan, Journal of the City Planning Institute of Japan Vol.46, No.3, 493-498.

Ota Creative Town Study Group.(2011).Ota Mono-machi BOOK 2011 -for Ota Creative Town, Japan: Ota Tourist Association.

Ota Creative Town Study Group.(2015).Ota Mono-machi BOOK 2014 -community development with manufacture in the future ,Japan: Ota Tourist Association

Yu Okamura, Taku Nohara, Susumu Kawahara and others. (2014). Local project with comprehensive approach of Fabrication, Community Development, and Tourism, Quarterly "Machi-dukuri”, 42 : Japan: Gakugei Publishing Corporation, 104-115 